\title{
Cocaine and Amphetamine Induce Overlapping but Distinct Patterns of AMPAR Plasticity in Nucleus Accumbens Medium Spiny Neurons
}

\author{
Jakub Jedynak', ${ }^{1,3}$ Matthew Hearing',3, Anna Ingebretson', Stephanie R Ebner', Matthew Kelly', \\ Rachel A Fischer', Saïd Kourrich ${ }^{1,4}$ and Mark J Thomas*,1,2 \\ 'Department of Neuroscience, University of Minnesota, Minneapolis, MN, USA; ${ }^{2}$ Department of Psychology, University of Minnesota, Minneapolis, \\ MN, USA
}

\begin{abstract}
Repeated exposure to psychostimulant drugs such as cocaine or amphetamine can promote drug-seeking and -taking behavior. In rodent addiction models, persistent changes in excitatory glutamatergic neurotransmission in the nucleus accumbens (NAc) appear to drive this drug-induced behavioral plasticity. To study whether changes in glutamatergic signaling are shared between or exclusive to specific psychostimulant drugs, we examined synaptic transmission from mice following repeated amphetamine or cocaine administration. Synaptic transmission mediated by AMPA-type glutamate receptors was potentiated in the NAc shell I0-14 days following repeated amphetamine or cocaine treatment. This synaptic enhancement was depotentiated by re-exposure to amphetamine or cocaine. By contrast, in the NAc core only repeated cocaine exposure enhanced synaptic transmission, which was subsequently depotentiated by an additional cocaine but not amphetamine injection during drug abstinence. To better understand the drug-induced depotentiation, we replicated these in vivo findings using an ex vivo model termed 'challenge in the bath,' and showed that drug-induced decreases in synaptic strength occur rapidly (within $30 \mathrm{~min}$ ) and require activation of metabotropic glutamate receptor 5 (mGluR5) and protein synthesis in the NAc shell, but not NAc core. Overall, these data demonstrate the specificity of neuronal circuit changes induced by amphetamine, introduce a novel method for studying drug challenge-induced plasticity, and define NAc shell medium spiny neurons as a primary site of persistent AMPA-type glutamate receptor plasticity by two widely used psychostimulant drugs.

Neuropsychopharmacology (20I6) 4I, 464-476; doi:I 0.I038/npp.20 I5.I68; published online 5 August 2015
\end{abstract}

\section{INTRODUCTION}

The nucleus accumbens (NAc) is a key constituent of the mesocorticolimbic circuit involved in the acquisition and expression of reward-dependent learning, and it is an important locus where drugs of abuse exert their rewarding and reinforcing effects (Hyman et al, 2006; Kalivas and Volkow, 2005). Cortical and limbic glutamatergic afferents to NAc medium spiny neurons (MSNs), the major neuron type in the NAc, drive neural activity and synaptic plasticity, and experience-dependent changes in the strength of these connections are central to the development and persistence of addiction-related behavior (Kombian and

*Correspondence: Professor MJ Thomas, Departments of Neuroscience and Psychology and Institute of Translational Neuroscience, University of Minnesota, 6-145 Jackson Hall, 32I Church Street South East, Minneapolis, MN 55455, USA, Tel: 612624 4963, Fax: 612624 79I, E-mail: tmhomas@umn.edu

${ }^{3}$ These authors contributed equally to this work.

${ }^{4}$ Current address: Department of Psychiatry, University of Texas Southwestern Medical Center, Dallas, TX, USA.

Received 24 December 2014; revised 24 April 2015; accepted 10 May 2015; accepted article preview online 12 June 2015
Malenka, 1994; Pennartz et al, 1993; Pennartz et al, 1990; Uchimura et al, 1989). An abundance of data indicates that this experience-dependent plasticity in NAc glutamatergic synaptic transmission is primarily expressed via dynamic changes in AMPA-type glutamate receptors (AMPARs), making these receptors a key target for studying how drug experiences modify behavior in models of addiction (Bowers et al, 2010; Kalivas and $\mathrm{Hu}, 2006$; Kauer and Malenka, 2007; Pierce and Wolf, 2013).

Neural adaptations that are conserved across multiple drug classes provide likely candidate mechanisms underlying core features of addiction. For example, exposure to cocaine and amphetamine produce a similar set of outcomes at both the behavioral and cellular level. Specifically, both promote development of behavioral sensitization and increase drug self-administration, enhance extracellular dopamine (DA) and glutamate levels in the NAc, and produce parallel adaptations in MSN intrinsic excitability (Kourrich and Thomas, 2009; Reid et al, 1997; Vezina, 2004; Xue et al, 1996). However, more drug-specific effects on NAc plasticity, most notably AMPAR expression, have also been demonstrated. For example, while repeated cocaine exposure produces robust and widespread increases in AMPAR 
subunit and cell surface expression (Boudreau and Wolf, 2005), the effects of repeated amphetamine on AMPAR cell surface levels are modest at best (Nelson et al, 2009). Furthermore, while it has been demonstrated that repeated cocaine promotes a time-dependent augmentation of AMPARmediated synaptic transmission in the NAc shell (Kourrich et al, 2007), electrophysiology data regarding amphetamineinduced alterations in AMPAR plasticity is lacking.

On the other hand, blocking AMPAR endocytosis during drug abstinence has been reported to prevent the expression of behavioral sensitization to amphetamine (Brebner et al, 2005), suggesting an important role for AMPARs in behaviors triggered by amphetamine re-exposure. These results raise questions of whether amphetamine alters excitatory synaptic strength in the NAc and whether the two major subdivision of the NAc, the core and shell, display similar adaptations. These areas are distinguished based on anatomical connectivity, involvement in reward-related responses, and have been shown to be differentially affected by drugs of abuse (Everitt et al, 1999; Heimer et al, 1991; Kourrich and Thomas, 2009; Zahm and Brog, 1992). Therefore, we investigated how repeated exposure to amphetamine and cocaine may differentially alter excitatory signaling in the NAc, focusing on region-specific changes in synaptic strength and AMPAR-mediated signaling in the core and shell. We also explored potential bidirectional changes in this plasticity elicited by re-exposure to these drugs during abstinence, and the potential underlying mechanisms of this plasticity using a novel ex vivo approach.

\section{MATERIALS AND METHODS}

\section{Animals}

Adult (P48-60) male C57BL/6J mice (Jackson Laboratories, Bar Harbor, Maine, USA) were group housed on a $12 \mathrm{~h}$ light/ dark cycle with food and water available ad libitum. All experiments were approved by the University of Minnesota Institutional Animal Care and Use Committee.

\section{Drug Treatment}

Mice were habituated to experimenter handling and injections (i.p.) over a 2-day period $\left(\mathrm{H}_{1-2}\right)$, followed by five consecutive once-daily injections of cocaine $(15 \mathrm{mg} / \mathrm{kg})$, amphetamine $(5 \mathrm{mg} / \mathrm{kg})$, or saline. For all test days, animals were habituated to testing chambers for $30 \mathrm{~min}$ and motor activity was monitored for 120 min following drug or saline administration. Following the final day of drug treatment, animals were returned to their home cage for 10-14 days. For experiments involving an in vivo drug re-exposure (challenge), animals were handled periodically throughout withdrawal in an attempt to mitigate any potential effects of stress during subsequent challenge injection. For in vivo drug challenge studies, cocaineand amphetamine-treated mice received an injection of either cocaine or amphetamine, after which activity was monitored and acute slices were prepared $24 \mathrm{~h}$ following testing. For experiments involving repeated amphetamine and/or in vivo amphetamine challenge (Figures 1 and 3), additional groups of mice were administered a saline
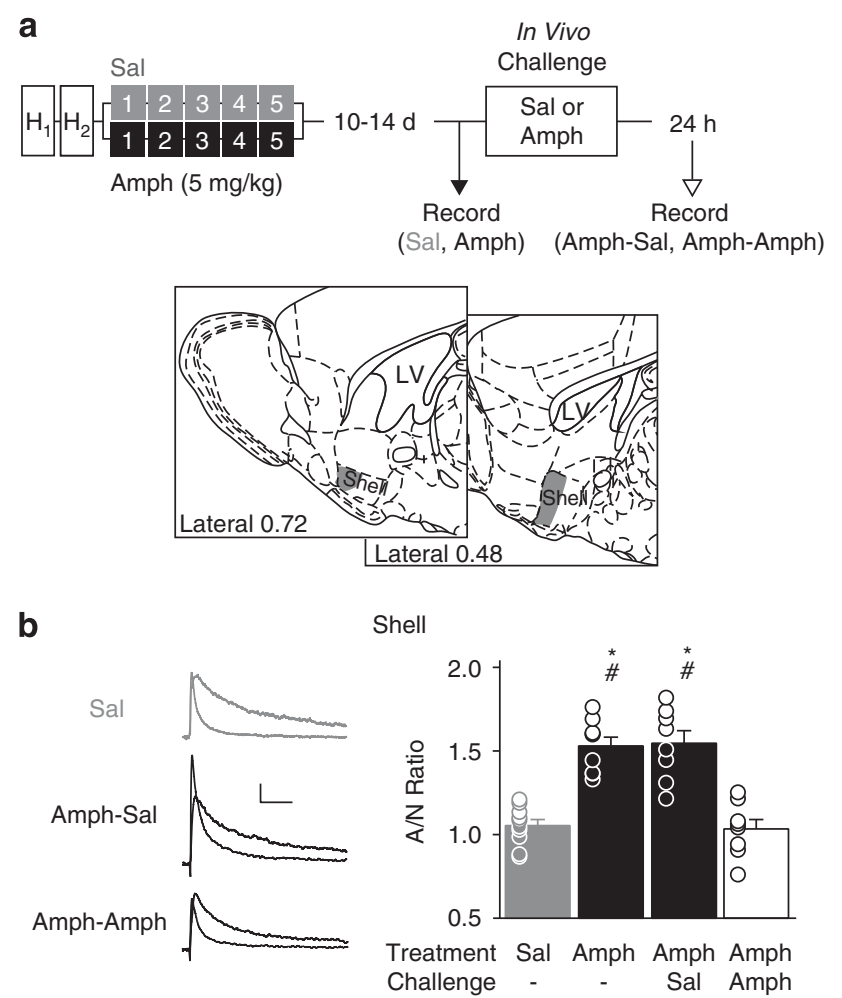

C

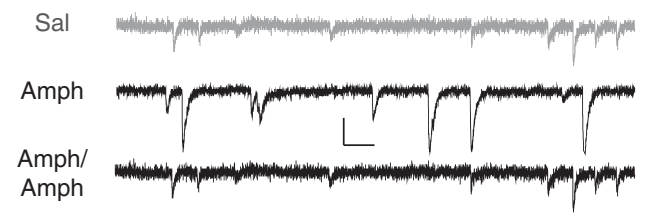

d
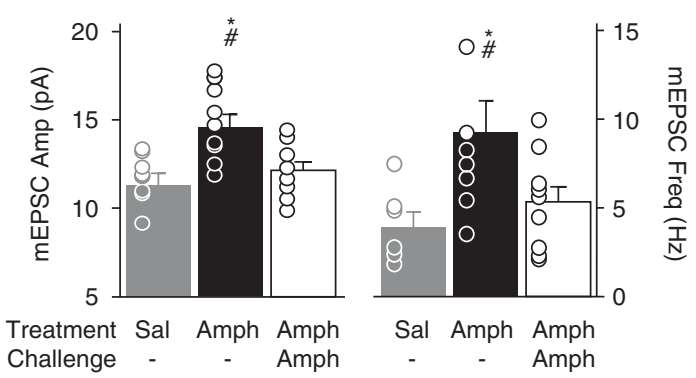

Figure I In vivo amphetamine induces bidirectional plasticity in synaptic AMPAR function in the NAc shell. (a) Experimental timeline (top) including 5 days of saline or amphetamine $(5 \mathrm{mg} / \mathrm{kg} ;$ i.p.) injections, a 10 -14-day abstinence period, and in some instances in amphetamine-treated mice a challenge injection of saline or amphetamine. Electrophysiological recordings were performed during abstinence or $24 \mathrm{~h}$ following a challenge injection. Recording locations were performed in the rostral portion of the NAc core or shell regions (gray) shown in anatomical schematics (bottom). (b) Representative AMPAR and NMDAR excitatory postsynaptic current (EPSC) traces (left) and mean AMPAR/NMDAR (A/N) ratios (right) from NAc shell neurons in saline+no challenge (Sal, gray; $n=10, N=6$ ), amphetamine+no challenge (Amph, black fill; $n=9, N=5$ ), amphetamine +saline challenge (Amph-Sal, black fill; $n=8, N=5$ ), and amphetamine +amphetamine challenge (Amph-Amph, black outline; $n=8, N=5$ ) mice. Scale bars, 20 pA/100 ms. (c) Representative miniature EPSCs (mEPSCs) traces. (d) Mean mEPSC amplitude ( $\mathrm{pA}$; left) and frequency ( $\mathrm{Hz}$; right) in the NAc shell (Sal: $n=6, N=3$; Amph: $n=10, N=5$; Amph-Amph: $n=8$, $N=3)$. Scale bars, $10 \mathrm{pA} / 100 \mathrm{~ms}$. All data are presented as mean \pm SEM. $n$, number of cells; $N$, number of animals. ${ }^{*} p \leqslant 0.05$ vs Sal; ${ }^{*} p \leqslant 0.05$ vs AmphAmph. AMPAR, AMPA-type glutamate receptor; Amph, Amphetamine; NAc, nucleus accumbens; Sal, saline. 
challenge injection to demonstrate that bidirectional changes in plasticity are drug dependent, rather than stress related to handling/injection, similar to previous findings with cocaine (Kourrich et al, 2007).

For initial ex vivo experiments (Figure 4) examining ex vivo amphetamine and cocaine 'bath challenge', tissue was transferred to a separate ACSF chamber containing $10 \mu \mathrm{M}$ amphetamine or $10 \mu \mathrm{M}$ cocaine, or ACSF (no challenge) for $10 \mathrm{~min}$. For inhibitor experiments (Figure 5), slices received: (1) no challenge (ex vivo bath exposure to ACSF); (2) ex vivo bath exposure to inhibitors MTEP $(5 \mu \mathrm{M}, 5 \mathrm{~min}$; mGluR5 antagonist) or cyclohexamide $(60 \mu \mathrm{M}, 30 \mathrm{~min}$; protein synthesis inhibitor) alone; (3) ex vivo bath exposure to cocaine only $(10 \mu \mathrm{M})$; or (4) ex vivo bath exposure to inhibitors followed by exposure to cocaine+inhibitor. Following drug treatment, slices were transferred to the recording chamber and allowed to recover for $30 \mathrm{~min}$. Recordings were obtained up to $2 \mathrm{~h}$ following transfer to the recording chamber.

\section{Electrophysiology}

Following 10-14 days of abstinence from psychostimulant drug treatment, mice were anesthetized with isofluorane and $250 \mu \mathrm{m}$ sagittal slices containing the NAc core or shell were prepared as previously described (Thomas et al, 2001). Slices were recovered for at least $30 \mathrm{~min}$ in ACSF solution saturated with $95 \% \quad \mathrm{O}_{2} / 5 \% \quad \mathrm{CO}_{2}$ containing (in $\mathrm{mM}$ ) $119 \mathrm{NaCl}, 2.5 \mathrm{KCl}, 1.0 \mathrm{NaH}_{2} \mathrm{PO}_{4}, 1.3 \mathrm{MgSO}_{4}$, $2.5 \mathrm{CaCl}_{2}, 26.2 \mathrm{NaHCO}_{3}$, and 11 glucose. For electrophysiological recordings, picrotoxin $(100 \mu \mathrm{M})$ was added to ACSF during AMPAR-mediated miniature excitatory postsynaptic current (mEPSC) and AMPA/NMDA ratio recordings to block GABAergic neurotransmission, while lidocaine $(0.7 \mathrm{mM})$ was present during $\mathrm{mEPSC}$ recordings to prevent action potentials. Cells were visualized in sagittal slices using infrared-differential contrast microscopy, and MSNs were identified by their morphology and typical hyperpolarized resting potential ( -70 to $-80 \mathrm{mV}$ ). Using an Axon Instruments Multiclamp 700B (Molecular Devices, Sunnyvale, CA, USA), MSNs were voltage clamped at $-80 \mathrm{mV}$ using electrodes $(3-5 \mathrm{M} \Omega$ ) containing a cesium-gluconate-based internal solution previously described (Kourrich et al, 2007). Data were filtered at $2 \mathrm{kHz}$ by Axonclamp amplifier (Molecular Devices) and digitized at $5 \mathrm{kHz}$ via custom Igor Pro software (Wavemetrics, Lake Oswego, OR, USA). At the beginning of each sweep, a depolarizing step $(4 \mathrm{mV}, 100 \mathrm{~ms})$ was generated by a Master- 8 stimulator (Jerusalem, Israel) to monitor series (10-40 M $\Omega)$ and input resistance ( $>400 \mathrm{M} \Omega$ ). For AMPAR/NMDAR and mEPSCs measurements, data collection and analysis were performed as previously described (Kourrich et al, 2007).

\section{Drugs}

Cyclohexamide, D-AP-5, and MTEP were purchased from Tocris Bioscience (Bristol, United Kingdom), while amphetamine and picrotoxin were purchased from Sigma Aldrich (St Louis, MO, USA). Cocaine was obtained from Boynton Pharmacy (University of Minnesota, Minneapolis, MN, USA).

\section{Data Analysis}

All data shown are expressed as a mean \pm SEM. AMPAR/ NMDAR ratios and mEPSCs were analyzed with a Student's $t$-test, one-way or two-way ANOVA using SigmaPlot (Systat Software) or GraphPad Prism (GraphPad Software, La Jolla, CA). Student-Newman-Keuls post hoc tests were used for pairwise comparisons when appropriate. The threshold for statistical significance was $p<0.05$.

\section{RESULTS}

\section{In vivo Amphetamine Induces Bidirectional Plasticity in Synaptic AMPAR Function in the NAc Shell}

Cocaine-induced AMPAR plasticity has been extensively studied in the NAc, while synaptic physiology data from amphetamine studies are scarce. To investigate potential long-lasting effects of repeated amphetamine exposure on glutamatergic synaptic transmission, we treated mice with an amphetamine regimen that produces robust psychomotor sensitization (eg, Kourrich and Thomas, 2009; Figure 3a) and prepared acute sagittal slices containing the NAc shell (Figure 1) or core (Figure 2) 10-14 days following the final drug (or saline) injection. In two additional groups of amphetamine-sensitized mice, we examined whether re-exposure to amphetamine (AmphAmph) or saline (Amph-Sal) with a challenge injection induced 'depotentiation,' a form of long-term synaptic depression (LTD) that has been observed $24 \mathrm{~h}$ following drug re-exposure (Boudreau et al, 2007; Kourrich et al, 2007; Pascoli et al, 2012; Rothwell et al, 2011). Interestingly, this form of experience-dependent LTD, whether it is induced by drug re-exposure or stress, appears to be restricted to animals with previous drug exposure (Kourrich et al, 2012; Kourrich et al, 2007; Pascoli et al, 2012; Rothwell et al, 2011). We measured the ratio of peak AMPAR- to NMDAR-mediated evoked synaptic currents in whole-cell recordings from MSNs in NAc shell and observed a $\sim 65 \%$ increase in the AMPAR/NMDAR ratio in cells from amphetamine- $v s$ saline-treated control mice. This was reversed by a single re-exposure to amphetamine, but not saline, during abstinence (Figure 1b, right; Sal $(1.05 \pm 0.04)$, Amph $(1.53 \pm 0.05)$, Amph-Sal (1.55 \pm 0.08$)$, Amph-Amph, $\left.1.03 \pm 0.06) ; \mathrm{F}_{(3,34)}=26.79 ; p<0.001\right)$. No significant differences were observed in AMPAR/NMDAR ratios between drug-naïve and saline-treated mice (data not shown; $t_{(17)}=0.011, p=0.991$ ).

As an additional test for drug-induced synaptic AMPAR plasticity, we recorded mEPSCs (Figure $1 \mathrm{c}$ and d). Both the amplitude (Figure 1d, left; Sal (11.25 \pm 0.59$)$, Amph $(14.57 \pm 0.85)$, Amph-Amph $(12.14 \pm 0.77) ; \mathrm{F}_{(2,22)}=6.778$, $p=0.005)$ and frequency (Figure 1d, right; Sal $(3.85 \pm 0.94)$, Amph $(9.22 \pm 1.81), \quad$ Amph-Amph $(5.28 \pm 0.92))$ of AMPAR mEPSCs were significantly increased in MSNs from amphetamine- $v s$ saline-treated mice and both parameters were reversed $24 \mathrm{~h}$ following amphetamine challenge (amplitude: $\mathrm{F}_{(2,22)}=6.778, p=0.005$ ); frequency: $\left.\mathrm{F}_{(2,20)}=4.20, p=0.03\right)$. Thus, the pattern of amphetamineinduced AMPAR plasticity bears a striking similarity to published data for cocaine in NAc shell (Kourrich et al, 2007; Rothwell et al, 2011; Kourrich et al, 2012). 
a
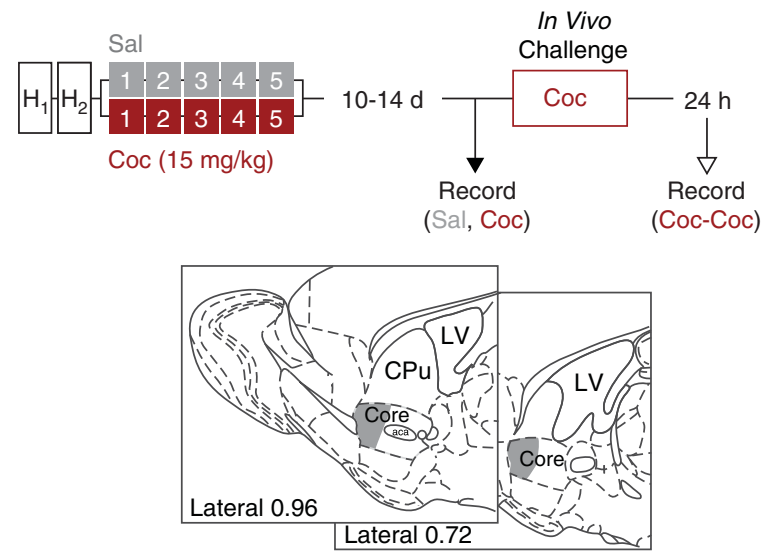

b

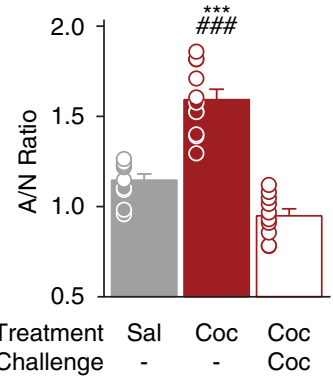

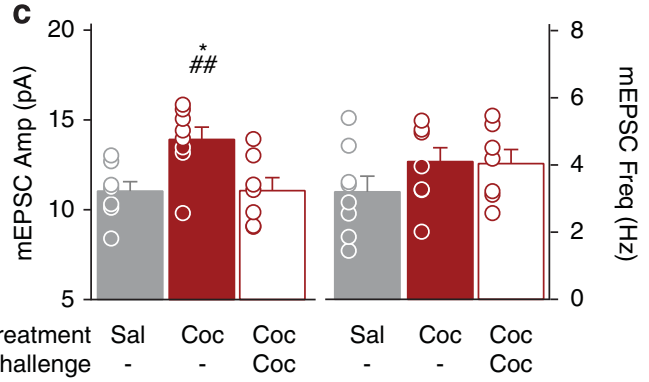

d

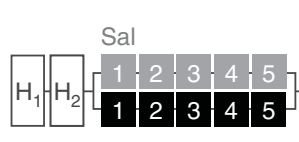
Amph $(5 \mathrm{mg} / \mathrm{kg})$

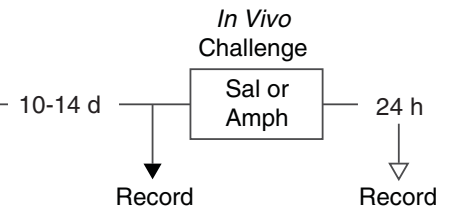

(Sal, Amph)

(Amph-Amph)
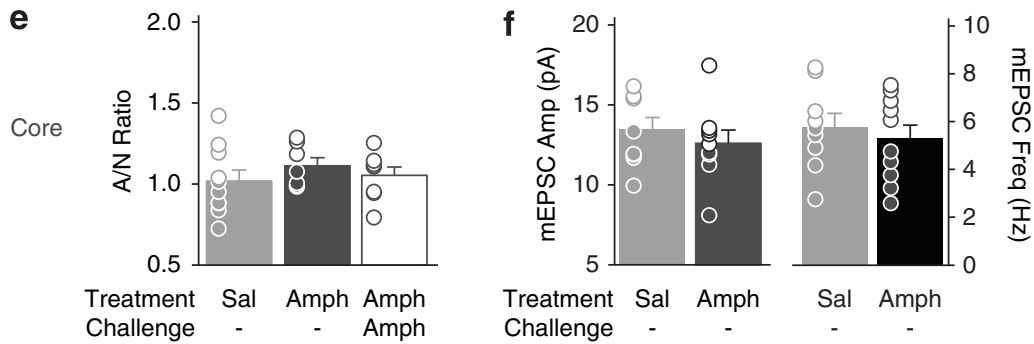

Treatment Sal Amph Sal Amph Challenge

Figure 2 In vivo cocaine, but not amphetamine, induces bidirectional AMPAR plasticity in the NAc core. (a) Experimental timeline including 5 days of saline or cocaine (15 mg/kg; i.p.) injections, a 10-14-day abstinence period, a challenge injection of cocaine, and electrophysiological recordings $24 \mathrm{~h}$ following cocaine challenge (left) and representation of recording locations within the rostral NAc core (right). (b) Mean AMPAR/NMDAR (A/N) ratios from NAc core neurons in saline+no challenge (Sal, gray; $n=10, N=4$ ), cocaine+no challenge (Coc, red; $n=11, N=4)$, and cocaine+cocaine challenge (Coc-Coc, red outline; $n=10, N=4)$ mice. (c) Mean mEPSC amplitude ( $p A$; left) and mEPSC frequency (Hz; right) in the NAc core from saline+no challenge (Sal, gray; $n=8, N=3$ ), cocaine+no challenge (Coc, red; $n=8, N=4)$, cocaine+cocaine challenge (Coc-Coc, red outline; $n=7, N=4)$ mice. (d) Experimental timeline including 5 days of saline or amphetamine $(5 \mathrm{mg} / \mathrm{kg}$; i.p.) injections, a I0-I4-day abstinence period, challenge injection of cocaine, and electrophysiological recordings $24 \mathrm{~h}$ following cocaine challenge. (e) Mean A/N ratios in NAc core neurons from saline+no challenge (Sal, $n=10, N=7$ ), amphetamine+no challenge (Amph, $n=7, N=4$ ), amphetamine+saline challenge (Amph-Sal, $n=6, N=4$ ), and amphetamine tamphetamine challenge (Amph-Amph, $n=8, N=4$ ) mice. Scale bars, $20 \mathrm{pA} / 100 \mathrm{~ms}$. (f) Mean mEPSC amplitude (left) and frequency (right) from Sal $(n=8-9, N=4)$ and Amph $(n=8-10, N=4)$ groups. All data are presented as mean \pm SEM. $n$, number of cells; $N$, number of animals. $* p \leqslant 0.05$, ***** $p \leqslant 0.00$ I vs Sal; ${ }^{\# \#} p \leqslant 0.01$ vs Coc-Coc, ${ }^{\# \#} p \leqslant 0.00$ I vs Coc-Coc. AMPAR, AMPA-type glutamate receptor; Amph, Amphetamine; NAc, nucleus accumbens; Sal, saline. 


\section{In vivo Cocaine, but not Amphetamine, Induces Bidirectional AMPAR Plasticity in the NAc Core}

While NAc shell MSNs exhibit cocaine-induced synaptic plasticity that is clearly bidirectional, little is known about AMPAR plasticity in the NAc core (Kourrich et al, 2007; Rothwell et al, 2011; Thomas et al, 2001). To test this directly, we measured AMPAR/NMDAR ratios 10-14 days following a sensitizing regimen of cocaine (5 once-daily, $15 \mathrm{mg} / \mathrm{kg}$ ) or saline, with a third group of cocaine-treated mice receiving a cocaine challenge $24 \mathrm{~h}$ prior to recording (Figure 2a). Consistent with previous observations (Conrad et al, 2008; Moussawi et al, 2011), repeated cocaine administration increased excitatory synaptic strength in NAc core MSNs from cocaine-treated mice compared with saline controls (Figure $2 b$; Sal $(1.15 \pm 0.03)$ vs Coc $(1.59 \pm 0.06)$ ). Furthermore, cocaine re-exposure reversed the potentiation to control levels (Coc-Coc: $0.95 \pm 0.04 ; \mathrm{F}_{(2,28)}=53.83$, $p<0.001)$. Repeated cocaine treatment also enhanced AMPAR mEPSC amplitude (Figure 2c, left; Sal (11.05 \pm $0.52)$ vs $\left.\operatorname{Coc}(13.92 \pm 0.68), \mathrm{F}_{(3,29)}=6.23, p=0.002\right)$. This potentiation was subsequently reversed $24 \mathrm{~h}$ following cocaine re-exposure (Coc-Coc: $11.084 \pm 0.72$ ).

Surprisingly, with amphetamine, AMPAR/NMDAR ratios in core were neither enhanced by repeated administration nor altered by re-exposure during abstinence (Figure 2e; Sal $(1.02 \pm 0.07)$, Amph (1.11 \pm 0.05$)$, Amph-Amph (1.05 \pm $\left.0.05) ; \mathrm{F}_{(3,28)}=0.44, p=0.73\right)$ ). As in the shell, no significant differences were observed in AMPAR/NMDAR ratios between drug-naïve and saline-treated mice (data not shown; $\left.t_{(15)}=0.257, p=0.801\right)$. Consistent with these AMPAR/NMDAR data, no significant differences were observed in AMPAR mEPSCs following treatment with repeated amphetamine (amplitude: Figure 2f, left; Sal $(13.48 \pm 0.74) v s$ Amph (12.61 \pm 0.82$) ; t_{(16)}=0.4779, p=0.6392$; frequency: Figure 2f, right, Sal (5.76 \pm 0.59$)$ vs Amph (5.29 \pm 0.57$)$; $\left.t_{(16)}=0.7926, p=0.4396\right)$. Interestingly, a trend toward a bimodal distribution is observed in mEPSC frequency. This could reflect differing effects of amphetamine within subpopulations of MSNs that express either DA D1 or D2 receptors, which have been observed with repeated cocaine exposure (Lee et al, 2006; Lobo et al, 2010; Pascoli et al, 2012) Together, these results demonstrate that in contrast to amphetamine's region-specific effect (shell only), cocaine induces bidirectional AMPAR plasticity in MSNs in both NAc shell and core.

\section{In vivo Amphetamine Depotentiates AMPAR Function in NAc Shell, but not Core, of Mice Sensitized to Cocaine}

While amphetamine fails to potentiate AMPAR function in the NAc core, we hypothesized that it may conserve the ability to depotentiate synapses on core MSNs that already exhibit enhanced AMPAR function. To test this, we took advantage of cocaine's ability to potentiate synaptic transmission in the NAc core. We first verified that amphetamine exposure during abstinence in cocaine-pretreated mice produced cross-sensitization, a phenomenon known to occur between psychostimulant drugs (Kalivas and Weber, 1988; Liu et al, 2007; Pierce and Kalivas, 1995; Vanderschuren et al, 1999). Following repeated saline or cocaine treatment and 10-14 days of drug abstinence (Figure 3a), mice received a challenge injection of saline (Sal-Sal, Coc-Sal) or amphetamine (Sal-Amph, Coc-Amph). Repeated cocaine treatment increased locomotion (meters traveled/90 min) on day 1 of exposure compared with saline controls, and locomotion was significantly higher on day $5 v s$ day 1 in cocaine-treated mice, indicating sensitization to cocaine (Figure $3 \mathrm{~b}$ left; $\left.\mathrm{F}_{(3,41)}=28.59, \quad p<0.001\right)$. Following 10-14 days of abstinence, amphetamine challenge increased locomotion (meters traveled per $20 \mathrm{~min}$ ) in saline- (Sal-Amph: $97.96 \pm 2.83$ ) and cocaine-treated (Coc-Amph: $156.29 \pm 10.98)$ mice compared with saline-challenged groups (Sal-Sal (21.1 \pm 5.46$)$, Coc-Sal $(29.59 \pm 4.68))$. Most importantly, this amphetamine challenge produced an augmented locomotor-activating effect in cocaine- $v s$ saline-pretreated mice, (Figure $3 \mathrm{~b}$ right; $\mathrm{F}_{(3,22)}=$ 62.82, $p<0.001$ ), confirming that this treatment produced cross-sensitization.

Twenty-four hours following in vivo amphetamine challenge, we measured synaptic AMPAR function in the NAc core and shell directly via AMPAR mEPSC recordings. For these and subsequent experiments, we focused on mEPSCs, as a direct measure of synaptic AMPAR function. In the core, we observed a significant effect of cocaine pretreatment $\left(\mathrm{F}_{(1,34)}=9.28, p=0.005\right)$ and drug challenge $\left(\mathrm{F}_{(1,34)}=4.57\right.$, $p=0.0 .04)$ on mEPSC amplitude (Figure $3 \mathrm{~d}$, left), with no significant interaction $\left(\mathrm{F}_{(1,34)}=0.127, p=0.724\right)$, suggesting that cocaine pretreatment increases mEPSC amplitude, and that while acute amphetamine augments mEPSC amplitude in drug naïve animals an amphetamine challenge does not further potentiate AMPAR function beyond that already induced by repeated cocaine (Sal-Sal (12.20 \pm 0.39$)$, SalAmph (14.47 \pm 0.59$)$, Coc-Sal (15.30 \pm 1.16$)$, Coc-Amph $(16.91 \pm 0.76)$. Analysis of mEPSC frequency (Figure $3 \mathrm{~d}$, right) revealed a main effect of challenge $\left(\mathrm{F}_{(1,34)}=7.46\right.$, $p=0.01)$, but not pretreatment $\left(\mathrm{F}_{(1,34)}=1.28, p=0.266\right)$, without significant interaction $\left(\mathrm{F}_{(1,34)}=0.085, p=0.773\right)$, indicating that acute amphetamine, but not repeated cocaine increases the frequency of these events in the NAc core (Sal-Sal (3.13 \pm 0.47$)$, Sal-Amph (4.84 \pm 0.62$)$, Coc-Sal $(3.94 \pm 0.80)$, Coc-Amph (5.32 \pm 0.36$)$.

In the NAc shell, unlike the core, an in vivo amphetamine challenge depotentiated cocaine-dependent increases in AMPAR mEPSC amplitude (Figure 3c left) and frequency (Figure $3 c$ right) to saline control levels (amplitude: Sal-Sal $(10.96 \pm 0.64)$, Coc-Sal $(14.29 \pm 1.26)$, Coc-Amph $(11.31 \pm$ $0.58), \mathrm{F}_{(1,28)}=6.67, p=0.02$; frequency: Sal-Sal (3.64 \pm 0.83$)$, Coc-Sal (7.49 \pm 1.17$)$, Coc-Amph $(3.89 \pm 0.59), F_{(1281)}=$ $7.56, p=0.01)$. However, an acute exposure to amphetamine in saline pretreated mice did not increase mEPSC amplitude (Sal-Amph: $11.98 \pm 0.27)$ or frequency $(4.62 \pm 0.69)$. To determine whether acute amphetamine may be promoting alterations in synaptic strength in NAc shell that are not reflected by changes in AMPARs, $A / N$ ratios were evaluated $24 \mathrm{~h}$ following acute exposure to saline or amphetamine; however, no significant difference was observed (Sal (1.16 \pm $0.04, n=8)$ vs Amph $(1.20 \pm 0.05, n=7) ; t_{(13)}=-0.751$, $p=0.47$; data not shown). Taken together, these data reveal several new features of amphetamine-induced plasticity in NAc MSNs. First, acute amphetamine exposure in drug naïve mice selectively increases AMPAR-mediated synaptic signaling in the NAc core. Second, only MSNs in the shell remain sensitive to acute amphetamine's effects following repeated cocaine exposure. Last, expression of cocaine/ 
a

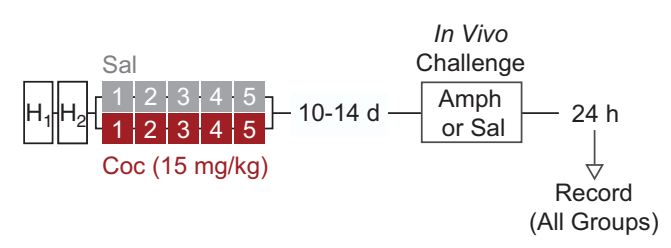

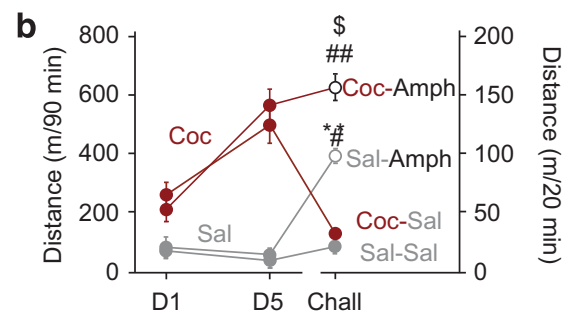

C

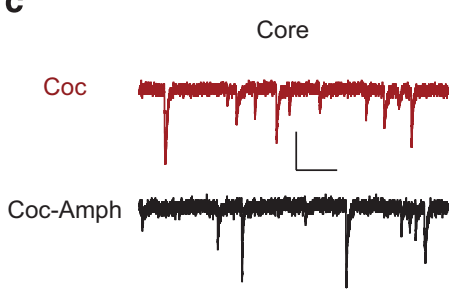

e

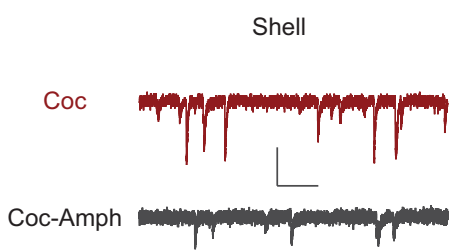

d
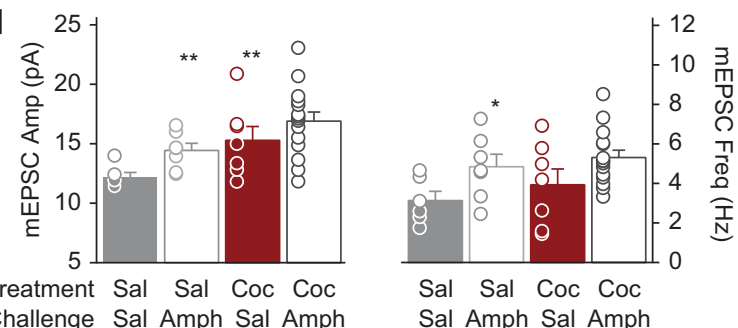
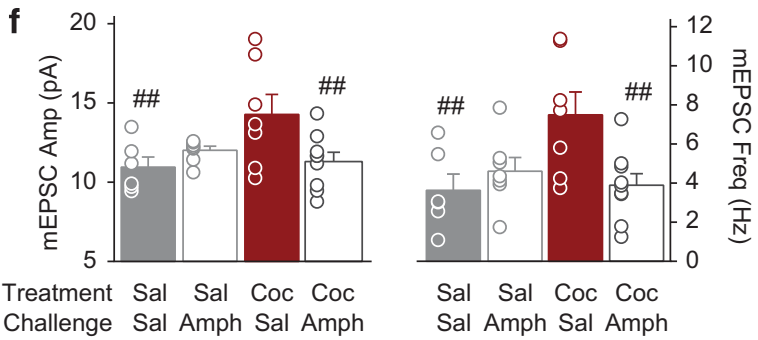

Figure 3 In vivo amphetamine depotentiates AMPAR function in NAc shell, but not core, of mice sensitized to cocaine. (a) Experimental timeline. Following 10-14-day abstinence from repeated cocaine or saline, mice were challenged with saline (Sal-Sal, gray fill; Coc-Sal, red fill), or amphetamine (Sal-Amph, gray outline; Coc-Amph, black outline). Brain slices for electrophysiology were prepared $24 \mathrm{~h}$ later. (b) Total distance traveled (90 min) following saline or cocaine injection on day I and 5 of repeated exposure (left) and total distance traveled during the first 20 min following a saline or amphetamine challenge (right). (c) NAc core representative traces and (d) mean amplitude (pA; right) and frequency ( $\mathrm{Hz}$; right) from Sal-Sal ( $n=6, N=3)$, Sal-Amph $(n=7, N=4)$, Coc-Sal $(n=7 ; N=4)$, and Coc-Amph $(n=15, N=6)$ treatment groups. (e) NAc shell representative mEPSC traces and (f) mean mEPSC amplitudes (left) and frequency (right) from NAc shell neurons in Sal-Sal $(n=6, N=4)$, Sal-Amph $(n=7, N=4), C o c-S a l \quad(n=7, N=3)$, and Coc-Amph $(n=9, N=6)$ mice. Scale, 20 pA/200 ms. All data are presented as the mean $\pm S E M$. $n$, number of cells; $N$, number of animals. * $p \leqslant 0.05$, $*_{*}{ }^{\prime} p \leqslant 0.0$ I vs Sal-Sal; ${ }^{*} p \leqslant 0.05,{ }^{\# \#} p \leqslant 0.01$ vs Coc-Sal, ${ }^{\$} p \leqslant 0.05$ vs Sal-Amph. AMPAR, AMPA-type glutamate receptor; Amph, amphetamine; NAc, nucleus accumbens; Sal, saline.

amphetamine cross-sensitization may rely on bidirectional plasticity within the shell.

\section{Ex vivo Cocaine and Amphetamine Challenge Mimics in vivo Challenge-Induced Plasticity in NAc Core and Shell}

To study the underlying cellular and molecular mechanisms responsible for the psychostimulant drug challenge-induced reversal of synaptic strength and AMPAR-mediated signaling, we investigated whether this plasticity could be studied ex vivo in the acute slice using a novel 'challenge-in-the-dish' approach. We first tested the ability of ex vivo cocaine bath application to induce depotentiation of synaptic strength in the NAc shell and core. For ex vivo psychostimulant challenge studies, a dose of $10 \mu \mathrm{M}$ was used as this concentration has been shown to promote plasticity in acute slice preparations without causing local anesthetic effects (Brodie and Dunwiddie, 1990; Schilstrom et al, 2006; Yasuda et al, 1984). Similar to in vivo psychostimulant drug exposure, incubation of acute slices for $10 \mathrm{~min}$ in cocaine $(10 \mu \mathrm{M})$ reversed in vivo cocaine-induced increases in synaptic strength in the NAc shell (Figure 4b; Sal $(0.70 \pm 0.02)$, Coc $(1.15 \pm 0.07), \quad$ Coc-Coc $\quad(0.81 \pm 0.03) ; \quad \mathrm{F}_{(2,16)}=17.15$, $p<0.001)$ and NAc core (Figure $4 \mathrm{~d}$; S $(0.85 \pm 0.03), \mathrm{C}$ $\left.(1.23 \pm 0.13), \mathrm{C}-\mathrm{C}(0.70 \pm 0.06) ; \mathrm{F}_{(2,13)}=7.81, p=0.009\right)$. We next investigated whether ex vivo psychostimulant drug application would mirror the drug- and brain-regionselective alterations in AMPAR-mediated signaling. In the NAc shell of cocaine-treated mice, bath application of either cocaine or amphetamine $(10 \mu \mathrm{M})$ reversed the in vivo cocaine-induced increase in mEPSC amplitude (Figure $4 \mathrm{c}$ left; Sal (11.69 \pm 0.43$)$, Coc (16.05 \pm 0.67$)$, Coc-Coc (10.52 \pm $0.32)$, Coc-Amph $\left.(11.86 \pm 0.64) ; \mathrm{F}_{(4,58)}=14.92, p<0.001\right)$ and frequency (Figure 4c right; Sal (6.01 \pm 0.66$)$, Coc $(9.59 \pm 1.02)$, Coc-Coc $(3.53 \pm 0.47)$, Coc-Amph $(6.37 \pm$ $\left.0.66) ; \mathrm{F}_{(3,41)}=10.92, p<0.001\right)$. Ex vivo cocaine application to acute slices from saline pretreated mice (Sal-Coc) did not significantly increase mEPSC amplitude $(13.66 \pm 0.7)$ or frequency $(4.95 \pm 0.73)$ compared with slices from salinetreated mice exposed to ACSF (Sal).

In the NAc core, bath application of cocaine, but not amphetamine, to slices from cocaine-pretreated mice reversed increases in mEPSC amplitude (Figure $4 \mathrm{e}$ left; 
a

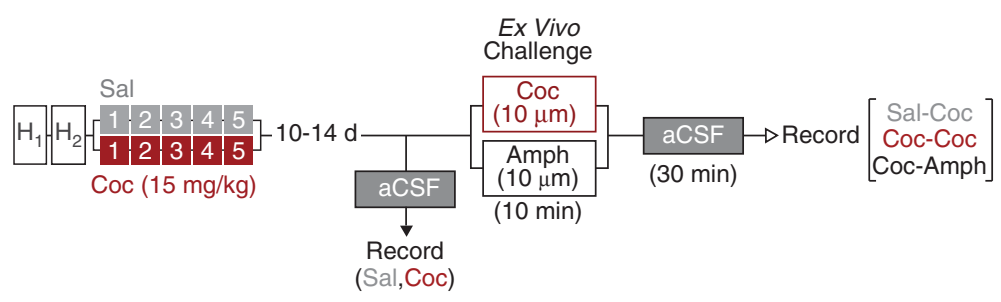

b

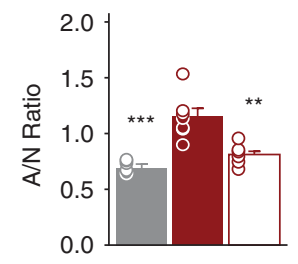

Treatment Sal Coc Coc Bath - - Coc

d

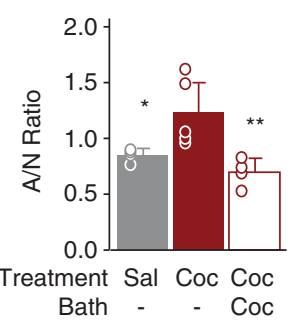

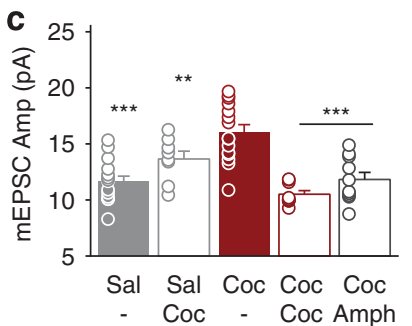
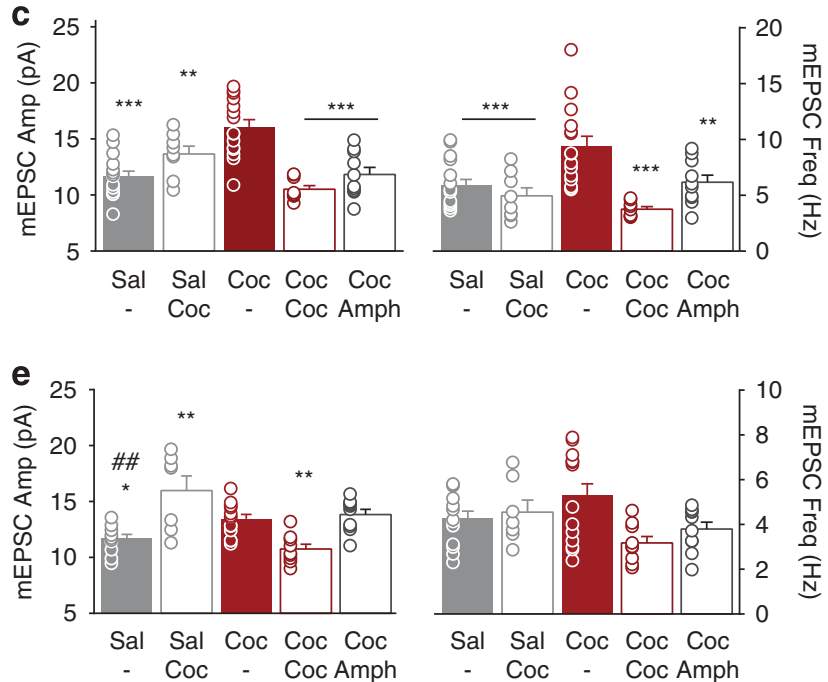

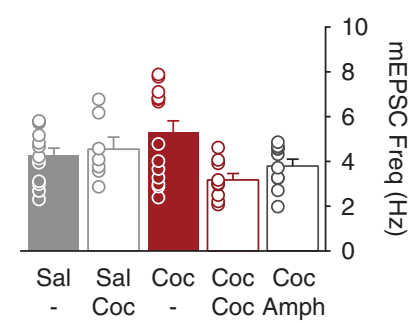

Figure 4 Ex vivo cocaine or amphetamine exposure mimics in vivo challenge-induced plasticity in NAc core and shell. (a) Experimental timeline. Following 10-14-day abstinence from repeated cocaine or saline treatment, electrophysiological recordings were performed in acute slices following no challenge (ex vivo bath exposure to ACSF only; Sal, Coc), or 30-120 min following a 10 min ex vivo incubation in either cocaine (Sal-Coc, Coc-Coc) or amphetamine (Coc-Amph). Following ex vivo bath exposure, slices recovered in recording ACSF for at least $30 \mathrm{~min}$. (b) Mean A/N ratios in the NAc shell from Sal+ACSF (Sal, gray; $n=4, N=3$ ), Coc+ACSF (Coc, red filled; $n=7, N=5$ ), and cocaine+ex vivo cocaine (Coc-Coc, red outlined; $n=6, N=5)$ mice. (c) Mean mEPSC amplitudes (left) and frequency (right) in the NAc Shell from saline+no challenge (Sal: $n=17, N=8)$, saline+ex vivo cocaine $($ Coc-Coc: $n=8, N=5)$, cocaine + no challenge (Coc: $n=15, N=8$ ), cocaine+ex vivo cocaine (Coc-Coc: $n=9, N=5)$, and cocaine+ex vivo amphetamine (Coc-Amph, black outlined, $n=10$, $N=6)$ mice. (d) Mean A/N ratios in the NAc core from Sal $(n=4, N=3), \operatorname{Coc}(n=5, N=3)$, and Coc-Coc $(n=5, N=4)$ groups. (e) Mean mEPSC amplitude (left) and frequency (right) in the NAc core from Sal $(n=13, N=7)$, Sal-Coc $(n=7, N=3), \operatorname{Coc}(n=14, N=7), \operatorname{Coc}-\operatorname{Coc}(n=9, N=5)$, and Coc-Amph $(n=10, N=5)$. n, number of cells; $N$, number of animals. ${ }^{*} p \leqslant 0.05, * * * 0.01, * * * * \leqslant \leqslant 0.00 \mid$ vs Coc, ${ }^{\# \#} p \leqslant 0.05$ vs Sal-Coc. Amph, amphetamine; mEPSC, miniature excitatory postsynaptic currents; NAc, nucleus accumbens; Sal, saline.

Sal (11.73 \pm 0.36$)$, Coc $(13.45 \pm 0.39)$, Coc-Coc $(10.75 \pm 0.43)$, Coc-Amph $\left.(13.84 \pm 0.46) ; \mathrm{F}_{(4,52)}=11.17, p<0.001\right)$. In contrast to NAc shell, we observed no significant differences in frequency between groups (Figure 4e right; $S(4.26 \pm 0.34)$, Sal-Coc ( $4.55 \pm 0.54)$, Coc $(5.28 \pm 0.54)$, Coc-Coc $(3.18 \pm 0.29)$, Coc-Amph $(3.80 \pm 0.31)$ ). Interestingly, ex vivo cocaine application to acute slices from saline pretreated animals (Sal-Coc) did significantly increase mEPSC amplitude $(15.98 \pm 1.31)$ and frequency $(4.55 \pm 0.54)$ in the NAc core. In summary, ex vivo psychostimulant exposure mirrors the bidirectional plasticity observed with in vivo challenge injections. This highlights the viability of using a challengein-the-dish approach to study mechanisms underlying psychostimulant-induced AMPAR depotentiation during drug abstinence.

\section{Cocaine-Induced Depotentiation Requires mGluR5 Activation and Protein Synthesis}

In the striatum, excitatory synapses on MSNs are capable of expressing LTD by several mechanisms (Luscher and Huber, 2010). In the NAc, activation of postsynaptic group I
mGluRs has been shown to promote reduced presynaptic glutamate release probability and increased trafficking of AMPARs (McCutcheon et al, 2011; Robbe et al, 2002). Thus, we investigated whether blockade of mGluR5-dependent signaling with bath application of the antagonist MTEP prevented the cocaine-induced depotentiation of AMPARmediated signaling in the NAc shell (Figure $5 b$ ) and core (Figure 5c).

As in previous experiments, cocaine treatment increased mEPSC amplitude in shell MSNs, which was subsequently reversed by an ex vivo cocaine bath challenge (Figure 5b left; Sal $(10.87 \pm 0.46)$, Coc $(14.62 \pm 0.90)$, Coc-Coc (10.52 \pm $0.32)$ ). However, incubation of acute slices in MTEP $(5 \mu \mathrm{M})$ prior to (and during) cocaine bath challenge prevented the bath cocaine-induced reductions in mEPSC amplitude (Figure 5b left; Coc-MTEP-Coc: $14.05 \pm 0.49 ; \mathrm{F}_{(6,71)}=5.93$, $p<0.001)$. Notably, while bath application of MTEP alone had no effect on baseline mEPSC amplitudes in slices from cocaine-treated animals (Coc-MTEP: $13.80 \pm 0.52$ ), MTEP application to slices from saline-treated animals (Sal-MTEP) significantly increased mEPSC amplitude (14.20 \pm 0.97$)$ but not frequency $(6.21 \pm 1.02)$ compared with saline-no 


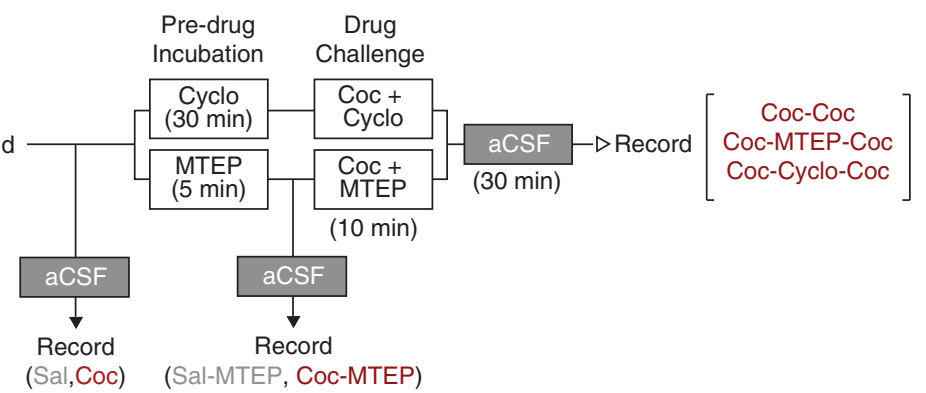

b

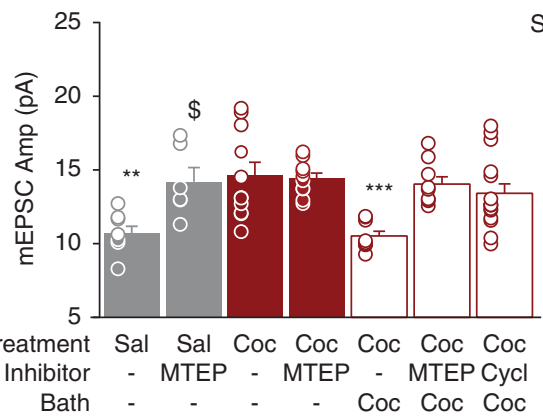

Shell

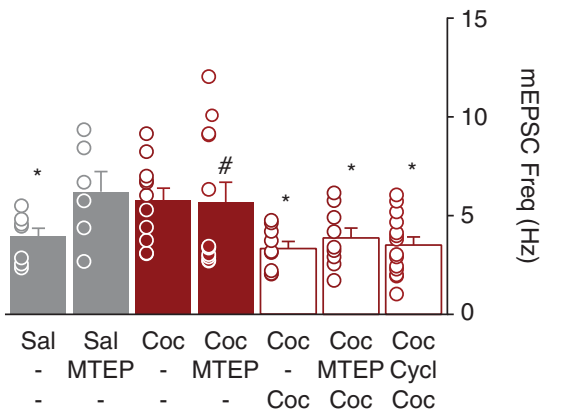

C

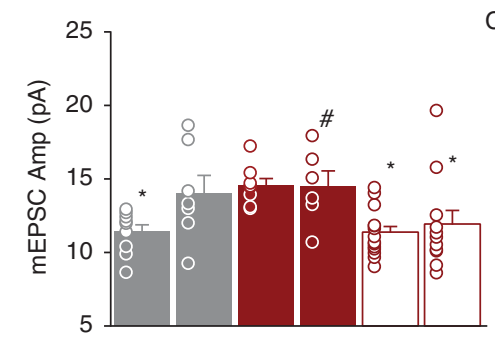

Pretreatment Sal Sal Coc Coc Coc Coc

Inhibitor - MTEP - MTEP - MTEP

Bath - - - - Coc Coc

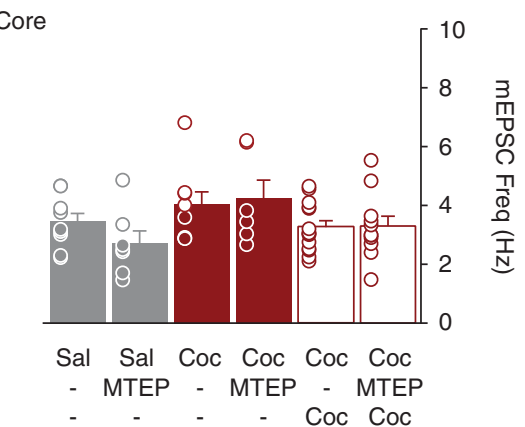

Figure 5 Cocaine-induced depotentiation of AMPAR-mediated signaling requires mGluR5 activation and protein synthesis. (a) Experimental timeline. Following I0-14-day abstinence from repeated cocaine or saline, electrophysiological recordings were performed in acute slices receiving one of the following treatments: (I) no bath challenge (ex vivo bath exposure to ACSF), (2) ex vivo bath exposure to MTEP (mGluR5 antagonist; $5 \mu$ M, I 5 min), (3) ex vivo bath exposure to cocaine only (10 $\mathrm{M}, 10 \mathrm{~min})$, or (4) ex vivo bath exposure to MTEP (5 min) or cyclohexamide (protein synthesis inhibitor; $60 \mu \mathrm{M}$, 30 min) followed by exposure to cocaine+inhibitor ( $10 \mathrm{~min}$ ). Following each treatment, slices were allowed to recover in recording ACSF for 30 min. (b) Mean mEPSC amplitude (left) and frequency (right) in NAc shell recordings from saline+no challenge (Sal, gray; $n=8, N=4$ ), saline+MTEP only (Sal-MTEP, gray; $n=6, N=3$ ), cocaine+no challenge (Coc, red filled; $n=11, N=5$ ), cocaine+MTEP only (Coc-MTEP, red filled; $n=10, N=4)$, cocaine+no inhibitor+cocaine bath challenge (Coc-Coc, red outlined; $n=9, N=5$ ), cocaine+MTEP+cocaine (Coc-MTEP-Coc, red outlined; $n=8, N=3$ ), and cocaine+cyclohexamide + cocaine (Coc-Cyclo-Coc, red outlined, $n=12, N=6$ ). (c) Mean mEPSC amplitude (left) and frequency (right) in NAc core recordings from saline+no challenge (Sal, gray; $n=9, N=4$ ), saline+MTEP only (Sal-MTEP, gray; $n=7, N=4$ ), cocaine+no challenge (Coc, red filled; $n=8, N=4$ ), cocaine+no inhibitor + cocaine (Coc-Coc, red outlined; $n=\mid 4, N=5$ ), and cocaine+MTEP+cocaine (Coc-MTEP-Coc, red outlined; $n=6, N=3$ ), n, number of cells; $N$, number of animals. ${ }^{*} p<0.05,{ }^{*} * p<0.01$, ${ }^{*} * * * 0.00$ I vs Coc; ${ }^{*} p \leqslant 0.05$ vs Coc-Coc+ACSF; ${ }^{\$} p \leqslant 0.05$ vs Sal. AMPAR, AMPA-type glutamate receptor; Amph, amphetamine; mEPSC, miniature excitatory postsynaptic currents; NAc, nucleus accumbens; Sal, saline.

challenge controls (Sal). A common mechanism for mGluRdependent LTD in many brain regions, including the striatum, is the reliance on rapid (in minutes) protein synthesis (Luscher and Huber, 2010; Yin et al, 2006). Consistent with this mechanism, we found that incubation of slices from cocaine-treated mice in the protein translation inhibitor, cyclohexamide $(60 \mu \mathrm{M})$, for $30 \mathrm{~min}$ prior to (and during) a cocaine bath challenge also prevented reductions in mEPSC amplitude (Coc-Cyclo-Coc: $13.45 \pm 0.60$; $\left.\mathrm{F}_{(6,66)}=5.93 p<0.001\right)$. Interestingly, neither MTEP nor cyclohexamide pretreatment prevented the cocaine challengeinduced reversal of AMPAR mEPSC frequency (Figure 5b, right; Sal $(3.95 \pm 0.42), \quad$ Coc $(5.78 \pm 0.61), \quad$ Coc-Coc
( $3.33 \pm 0.36)$, Coc-MTEP-Coc $(3.87 \pm 0.50)$, Coc-Cyclo-Coc $\left.(3.52 \pm 0.56) ; \mathrm{F}_{(6,66)}=3.90, p=0.002\right)$. MTEP application to slices from cocaine-treated mice did not significantly alter mEPSC frequency (Coc-MTEP: 6.27 \pm 1.11 ) compared with cocaine no challenge controls (Coc), and trended $(p=0.089)$ toward increasing mEPSC frequency in slices from salinetreated mice (Sal-MTEP: $6.21 \pm 1.01$ ).

In the NAc core, cocaine significantly increased mEPSC amplitude compared with saline controls (Figure 5c); however, unlike the shell, incubation of acute slices in MTEP prior to cocaine bath challenge failed to prevent reductions in mEPSC amplitude (Figure 5c left; Sal $(11.41 \pm 0.48)$, Coc $(14.20 \pm 1.08)$, Coc-Coc (11.30 \pm 0.43$)$, Coc-MTEP-Coc 
$\left.(11.85 \pm 0.97) ; F_{(5,57)}=4.57, p=0.002\right)$. MTEP application alone had no effect on mEPSC amplitude in slices from saline- (Sal-MTEP: $14.20 \pm 1.08$ ) or cocaine-treated (CocMTEP: $14.51 \pm 1.04)$ mice compared with their respective controls. No significant effects were observed on mEPSC frequency in the NAc core (Figure $5 \mathrm{c}$ right; $\mathrm{F}_{(5,57)}=2.04$, $p=0.09)$. Thus, while the phenomena of cocaine-induced depotentiation in the NAc core $v s$ shell are outwardly similar, the mechanisms appear to be different, with NAc shell depotentiation relying on mGluR5 activation and protein translation.

\section{DISCUSSION}

Our study demonstrates four key findings. First, repeated in vivo amphetamine treatment produces long-term changes in AMPAR synaptic transmission selectively in the NAc shell, while acute amphetamine treatment produces transient increases in the NAc core. Second, similar to previous findings in the shell, repeated cocaine promotes bidirectional and AMPAR-dependent changes in MSNs of the core. Third, using the ex vivo 'challenge-in-the-bath' approach is feasible for studying the mechanisms of psychostimulant-induced synaptic depotentiation, as this approach mirrored druginduced plasticity observed with in vivo drug re-exposure. Finally, re-exposure to cocaine during abstinence depotentiates AMPAR signaling in NAc shell, but not NAc core, MSNs via an mGluR5- and protein synthesis-dependent mechanism.

\section{NAc Subregion-Specific Effects of Amphetamine on Synaptic AMPAR Function}

The current study provides the first electrophysiological evidence that repeated amphetamine induces long-lasting increases in MSN synaptic strength in the NAc shell, but not core, and that this plasticity reflects increased AMPAR signaling. While the selectivity of this plasticity is striking, the lack of widespread synaptic AMPAR potentiation in NAc is consistent with previously reported biochemical studies, demonstrating that repeated in vivo amphetamine increased AMPAR surface expression in NAc shell-enriched but not NAc core-enriched tissue punches (Nelson et al, 2009). Although the exact implications are unclear, regional differences in amphetamine's ability to induce AMPAR plasticity might help to explain previous region-selective effects on drug-induced behavior. For example, microinfusion of amphetamine directly in the shell, but not core, elicits sensitized locomotor responding in cocaine-pretreated animals (Pierce and Kalivas, 1995). Consistent with this, the present study demonstrates that acute amphetamine exposure following repeated cocaine depotentiated AMPAR signaling selectively within the NAc shell. This raises intriguing questions about whether other drugs of abuse known to produce cross-sensitization with psychostimulant drugs might also produce depotentiation in the NAc shell, and whether this may be a common mechanism that promotes the expression of sensitization following chronic drug exposure.

We demonstrate that AMPAR signaling was selectively increased in the shell region following 10-14 days of abstinence from repeated amphetamine, while $24 \mathrm{~h}$ following an acute exposure AMPAR potentiation was confined to MSNs of the core. The mechanism that accounts for this region-specific difference in plasticity between acute and repeated amphetamine is not yet clear. One possible factor is the difference in amphetamine's ability to increase extracellular DA in core $v s$ shell. For example, in drug-naïve animals, the core is more sensitive to amphetamine than the shell-producing a larger increase in extracellular DA at lower concentrations of the drug (Siciliano et al, 2014). Interestingly, following repeated amphetamine treatment, amphetamine-induced increases in extracellular DA appear to be enhanced in shell, but not core (Giorgi et al, 2005; Pierce and Kalivas, 1995). As increased DA receptor signaling can promote AMPAR trafficking to synapses in NAc MSNs (Sun et al, 2008), it remains to be determined whether changes in the DA-enhancing properties of amphetamine in core $v s$ shell might explain the regionselective AMPAR plasticity effects of acute $v s$ repeated amphetamine.

\section{Ex vivo Psychostimulant Exposure Induces Synaptic Depotentiation}

The 'challenge-in-a-dish' approach provides a potentially advantageous means to study drug-induced neuronal plasticity as it greatly facilitates co-application of antagonists or inhibitors with cocaine. Despite the fact that network connections to the NAc are reduced in a brain slice preparation, ex vivo cocaine bath application was able to promote synaptic depotentiation that mirrored previous results in which in vivo cocaine reduced synaptic transmission in cocaine-pretreated mice (Kourrich et al, 2007; Pascoli et al, 2012; Rothwell et al, 2011). Interestingly, ex vivo cocaine also increased mEPSC amplitude (but not frequency) selectively within the NAc core $30 \mathrm{~min}$ following bath exposure. While it was previously shown that increases in AMPAR surface expression in the NAc occur $24 \mathrm{~h}$ but not $30 \mathrm{~min}$ or $2 \mathrm{~h}$ following acute cocaine exposure (Ferrario et al, 2010), NAc core and shell subregions were not evaluated separately. Furthermore, both ex vivo cocaine and amphetamine recapitulated their in vivo depotentiation effects-reversing cocaine-induced increases in AMPAR signaling in the NAc core (cocaine) and NAc shell (cocaine and amphetamine). While it is difficult to exclude the possibility that synaptic properties are modified as a result of slice preparation and maintenance, the striking consistency in results between in vivo and ex vivo experiments suggests that the cellular and molecular machinery responsible for reducing synaptic transmission remains intact and that this type of preparation can be useful for investigating the mechanisms by which psychostimulant exposure promotes bidirectional AMPAR plasticity.

Previous work from our laboratory demonstrated that depotentiation of AMPAR/NMDAR ratios is present $24 \mathrm{~h}$ after the last exposure during abstinence (Kourrich et al, 2007) and as early as $2 \mathrm{~h}$ following re-exposure to cocaine (Kourrich et al, 2007; Rothwell et al, 2011). Recent data indicate that this depotentiation is specific to AMPARmediated synaptic transmission and occurs as early as $1 \mathrm{~h}$ following cocaine re-exposure (Pascoli et al, 2012). The challenge-in-a-dish ex vivo method should be useful in 
further defining the induction timeframe. Here, we used a between-slice (or before vs after) design for measuring psychostimulant drug effects on synaptic AMPAR function and found that depotentiation occurs within $30 \mathrm{~min}$ of exposure-the earliest time point yet measured. Future studies, using a within-cell design and monitoring synaptic transmission as cocaine or amphetamine is applied, should be able to pin down the time course of induction even more precisely, providing data useful for defining the possible role for this plasticity in psychostimulant-induced changes in behavior.

\section{Mechanisms Underlying Synaptic Depotentiation}

Of the signaling pathways engaged by psychostimulant drug exposure, two are well known: increased dopaminergic and glutamatergic transmission. DA concentration increases in the extracellular space following exposure to either cocaine or amphetamine in vivo and ex vivo (Castañeda et al, 1988; Di Chiara and Imperato, 1988; Imperato and Di Chiara, 1984; Kelly and Wightman, 1987; Pontieri et al, 1995). In terms of our current study, the resulting increase in dopaminergic signaling is very likely a significant contributor to the induction of drug-induced depotentiation in the NAc shell. For example, while DA D1 receptor activation has been shown to promote the delivery of AMPARs to the surface of NAc MSNs (Chao et al, 2002), after repeated bouts of DA exposure, this effect of D1R activation is lost (Sun et al, 2008). Furthermore, a recent study found that prolonged ex vivo D1 receptor activation, while having no effect on AMPARs in NAc shell MSNs during the first several days of abstinence from cocaine self-administration, reduced the AMPAR/NMDAR if delivered following several weeks of abstinence (Ortinski et al, 2012). Taken together, these results suggest that D1R activation may have a key role in the drug re-exposure plasticity observed here.

Our initial efforts here to characterize the mechanisms responsible for inducing cocaine-dependent depotentiation in the NAc support a requirement for the glutamate receptor, mGluR5. Evidence from in vivo and ex vivo studies show that glutamatergic transmission in NAc and striatum can be enhanced during psychostimulant re-exposure (Bamford et al, 2008; McFarland et al, 2003; Park et al, 2002; Pierce et al, 1996; Reid et al, 1997). This short-term increase in glutamate provides a means by which mGluR5 receptors could be engaged. On one hand, a role for mGluR5 in druginduced depotentiation is not surprising. There is substantial literature documenting mGluR-mediated synaptic plasticity in the striatum and its molecular and cellular mechanisms (Gubellini et al, 2004; Luscher and Huber, 2010; Wang et al, 2004). Group 1 mGluRs (mGluR1 and mGluR5) are localized postsynaptically in a perisynaptic area that surrounds ionotropic receptors and are thus well positioned to regulate excitatory synaptic strength by redistributing AMPARs (Lujan et al, 1996), and activation of these mGluRs in the NAc is known to promote long-lasting reductions in presynaptic glutamate release probability (Robbe et al, 2002) and internalization of AMPARs (Mangiavacchi and Wolf, 2004; McCutcheon et al, 2011). On the other hand, mGluR5 dependence of cocaine-induced depotentiation presents an apparent conundrum. Recent data suggest that in vitro induction of mGluR5-dependent LTD in NAc shell slices from cocaine-treated animals is disrupted, rather than facilitated (Huang et al, 2014; Huang et al, 2011). These data match a broader pattern of disruption of mGluR5-dependent LTD in other striatal regions and the bed nucleus of the stria terminalis in brain slices from cocaine-treated animals (Grueter et al, 2006; Grueter et al, 2008; Knackstedt et al, 2014) that may be related to reduced mGluR5 expression (Huang et al, 2011) or decreased presence on the cell surface (Knackstedt et al, 2010). These studies have employed the useful strategy of applying trains of electrical stimulation or directly activating mGluRs with agonist (eg, DHPG) to induce plasticity ex vivo. While experiments of this kind provide invaluable and logical starting points from which putative mechanisms for the drug-induced plasticity observed here can be determined, it is difficult to predict the degree to which the mechanisms of these types of plasticity (ie, stimulation- $v s$ agonist- $v s$ drug-induced) will overlap. Determining the relationship between these forms of LTD/ depotentiation and how they are modulated by prior in vivo drug exposure, will require a much more thorough understanding of the signaling pathways initiated by the specific plasticity-inducing stimulus.

The inability of MTEP to prevent cocaine-induced depotentiation within the NAc core may be due in part to reductions in mGluR5 receptor availability. In support of this, mGluR5 protein expression is significantly reduced in the medial portion of the NAc core 21 days following a similar regimen of cocaine administration (Swanson et al, 2001). In addition, reductions in the intracellular scaffolding protein, Homer1b/c, which is known to functionally link mGluR5 with ionotropic glutamate receptors (Naisbitt et al, 1999; Tu et al, 1999; Naisbitt et al, 1999; Tu et al, 1999) is also reduced in the core (Swanson et al, 2001), suggesting a possible reduction in mGluR5 signaling efficacy. In contrast, in the NAc shell, mGluR5 antagonism reduces cocaineand cue-induced reinstatement of drug-seeking behavior (Kumaresan et al, 2009) and cocaine-induced reductions in AMPAR signaling (present study), indicating that to some degree mGluR5-mediated signaling in this region remains intact. Interestingly, in the NAc shell, MTEP application to slices from saline-treated mice increased mEPSC amplitude, suggesting that mGluR5 activity under basal (saline) conditions may normally serve to temper synaptic potentiation (Robbe et al, 2002). Consistent with this possibility, mGluR5 agonist-independent receptor activity has been observed in other brain regions (eg, cerebellum); however, whether this occurs in striatal MSNs remains unknown (Ango et al, 2001). While the failure of MTEP alone to increase AMPAR function in slices from cocaine-treated mice may reflect an occlusion, as AMPAR signaling is already enhanced following cocaine treatment, it is also possible that repeated cocaine exposure alters the functional capability of mGluR5dependent signaling normally observed under basal conditions.

A common cellular mechanism for mGluR-LTD and AMPAR endocytosis in many brain regions, including the striatum, is a reliance on protein synthesis that can occur rapidly in the dendrites (Huber et al, 2000; Yin et al, 2006). For example, activity-regulated cytoskeletal associated (Arc) protein is synthesized within dendrites in an activity- and group I mGluR-dependent manner where it associates with components of AMPAR endocytosis machinery and has 
been shown to actively maintain LTD (Park et al, 2008; Waung et al, 2008). Within striatal regions, Arc protein expression is robustly induced following re-exposure to cocaine-paired stimuli and modulates extinction of drugseeking behavior (Hearing et al, 2011; Hearing et al, 2008). In addition, mGluR activation has been shown to induce rapid translation of striatal-enriched protein tyrosine phosphatase (STEP), which also downregulates AMPAR surface expression and may actively maintain endocytosis rates (Luscher and Huber, 2010; Zhang et al, 2008). Acute exposure to both amphetamine and cocaine alters phosphorylation of STEP in striatal regions and inactivation of STEP prevents cocaineinduced reductions in AMPAR-mediated currents in MSNs (Chiodi et al, 2014; Sun et al, 2007; Tashev et al, 2009; Valjent et al, 2005). However, the degree to which alterations in STEP activity may occur in response to psychostimulant re-exposure is unknown. In summary, although further studies will be required to identify the critical 'LTD proteins' responsible for the cocaine-induced depotentiation, the requirement for local protein translation helps identify Arc and STEP as potential candidates-a possibility that can be explored using the novel 'challenge in the bath' approach.

\section{CONCLUSION}

Beyond cocaine, little is known about the ability of psychostimulant drugs to alter excitatory neurotransmission in the NAc. We report that repeated amphetamine and cocaine exposure differentially alters glutamatergic neurotransmission in NAc shell and core. To investigate the amphetamine core-shell dichotomy, we employed cross-sensitization and 'challenge-in-a-dish' paradigms that further demonstrated the core's insensitivity to enduring changes following repeated amphetamine. Use of the novel ex vivo method also allowed the identification of mGluR5 activation and protein synthesis as necessary for cocaine-induced depotentiation, suggesting a means by which mGluR antagonists might modulate drug-related behaviors.

\section{FUNDING AND DISCLOSURE}

This work was supported by funding from the University of Minnesota Foundation, the Breyer-Longden Family Research Fund, and the National Institute on Drug Abuse to MJT (R01 DA019666, K02 DA035459) and to JJ, MK, AI, and SRE (T32 DA007234). The authors declare no conflict of interest.

\section{ACKNOWLEDGMENTS}

We thank members of the Thomas lab and Dr Greg Hjelmstad for comments on an earlier version of the manuscript.

\section{REFERENCES}

Ango F, Prezeau L, Muller T, Tu JC, Xiao B, Worley PF et al (2001). Agonist-independent activation of metabotropic glutamate receptors by the intracellular protein Homer. Nature 411: 962-965.
Bamford NS, Zhang H, Joyce JA, Scarlis CA, Hanan W, Wu NP et al (2008). Repeated exposure to methamphetamine causes longlasting presynaptic corticostriatal depression that is renormalized with drug readministration. Neuron 58: 89-103.

Boudreau AC, Reimers JM, Milovanovic M, Wolf ME (2007). Cell surface AMPA receptors in the rat nucleus accumbens increase during cocaine withdrawal but internalize after cocaine challenge in association with altered activation of mitogen-activated protein kinases. J Neurosci 27: 10621-10635.

Boudreau AC, Wolf ME (2005). Behavioral sensitization to cocaine is associated with increased AMPA receptor surface expression in the nucleus accumbens. J Neurosci 25: 9144-9151.

Bowers MS, Chen BT, Bonci A (2010). AMPA receptor synaptic plasticity induced by psychostimulants: the past, present, and therapeutic future. Neuron 67: 11-24.

Brebner K, Ahn S, Phillips AG (2005). Attenuation of d-amphetamine self-administration by baclofen in the rat: behavioral and neurochemical correlates. Psychopharmacology 177: 409-417.

Brodie MS, Dunwiddie TV (1990). Cocaine effects in the ventral tegmental area: evidence for an indirect dopaminergic mechanism of action. Naunyn Schmiedebergs Arch Pharmacol 342: 660-665.

Castañeda E, Becker J, Robinson T (1988). The long-term effects of repeated amphetamine treatment in vivo on amphetamine, $\mathrm{KCl}$ and electrical stimulation evoked striatal dopamine release in vitro. Life Sci 42: 2447-2456.

Chao SZ, Ariano MA, Peterson DA, Wolf ME (2002). D1 dopamine receptor stimulation increases GluR1 surface expression in nucleus accumbens neurons. J Neurochem 83: 704-712.

Chiodi V, Mallozzi C, Ferrante A, Chen JF, Lombroso PJ, Di Stasi AM et al (2014). Cocaine-induced changes of synaptic transmission in the striatum are modulated by adenosine A2A receptors and involve the tyrosine phosphatase STEP. Neuropsychopharmacology 39: 569-578.

Conrad KL, Tseng KY, Uejima JL, Reimers JM, Heng LJ, Shaham Y et al (2008). Formation of accumbens GluR2-lacking AMPA receptors mediates incubation of cocaine craving. Nature 454: $118-121$.

Di Chiara G, Imperato A (1988). Drugs abused by humans preferentially increase synaptic dopamine concentrations in the mesolimbic system of freely moving rats. Proc Natl Acad Sci USA 85: 5274-5278.

Everitt BJ, Parkinson JA, Olmstead MC, Arroyo M, Robledo P, Robbins TW (1999). Associative processes in addiction and reward. The role of amygdala-ventral striatal subsystems. Ann NY Acad Sci 877: 412-438.

Ferrario CR, Li X, Wang X, Reimers JM, Uejima JL, Wolf ME (2010). The role of glutamate receptor redistribution in locomotor sensitization to cocaine. Neuropsychopharmacology 35: $818-833$.

Giorgi O, Piras G, Lecca D, Corda MG (2005). Differential activation of dopamine release in the nucleus accumbens core and shell after acute or repeated amphetamine injections: a comparative study in the Roman high- and low-avoidance rat lines. Neuroscience 135: 987-998.

Grueter BA, Gosnell HB, Olsen CM, Schramm-Sapyta NL, Nekrasova T, Landreth GE et al (2006). Extracellular-signal regulated kinase 1-dependent metabotropic glutamate receptor 5 -induced long-term depression in the bed nucleus of the stria terminalis is disrupted by cocaine administration. J Neurosci 26: 3210-3219.

Grueter BA, McElligott ZA, Robison AJ, Mathews GC, Winder DG (2008). In vivo metabotropic glutamate receptor 5 (mGluR5) antagonism prevents cocaine-induced disruption of postsynaptically maintained mGluR5-dependent long-term depression. J Neurosci 28: 9261-9270.

Gubellini P, Pisani A, Centonze D, Bernardi G, Calabresi P (2004). Metabotropic glutamate receptors and striatal synaptic plasticity: 
implications for neurological diseases. Prog Neurobiol 74: 271-300.

Hearing MC, Schwendt M, McGinty JF (2011). Suppression of activity-regulated cytoskeleton-associated gene expression in the dorsal striatum attenuates extinction of cocaine-seeking. Int $J$ Neuropsychopharmacol 14: 784-795.

Hearing MC, See RE, McGinty JF (2008). Relapse to cocaineseeking increases activity-regulated gene expression differentially in the striatum and cerebral cortex of rats following short or long periods of abstinence. Brain Struct Funct 213: 215-227.

Heimer L, Zahm DS, Churchill L, Kalivas PW, Wohltmann C (1991). Specificity in the projection patterns of accumbal core and shell in the rat. Neuroscience 41: 89-125.

Huang C-CC, Liang Y-CC, Lee C-CC, Hsu K-SS (2014). Cocaine withdrawal impairs mGluR5-dependent long-term depression in nucleus accumbens shell neurons of both direct and indirect pathways. Mol Neurobiol (doi:10.1007/s12035-014-8926-z).

Huang CC, Yeh CM, Wu MY, Chang AY, Chan JY, Chan SH et al (2011). Cocaine withdrawal impairs metabotropic glutamate receptor-dependent long-term depression in the nucleus accumbens. J Neurosci 31: 4194-4203.

Huber KM, Kayser MS, Bear MF (2000). Role for rapid dendritic protein synthesis in hippocampal mGluR-dependent long-term depression. Science 288: 1254-1257.

Hyman SE, Malenka RC, Nestler EJ (2006). Neural mechanisms of addiction: the role of reward-related learning and memory. Ann Rev Neurosci 29: 565-598.

Imperato A, Di Chiara G (1984). Trans-striatal dialysis coupled to reverse phase high performance liquid chromatography with electrochemical detection: a new method for the study of the in vivo release of endogenous dopamine and metabolites. J Neurosci 4: 966-977.

Kalivas PW, Hu XT (2006). Exciting inhibition in psychostimulant addiction. Trends Neurosci 29: 610-616.

Kalivas PW, Volkow ND (2005). The neural basis of addiction: a pathology of motivation and choice. Am J Psychiatry 162: 1403-1413.

Kalivas PW, Weber B (1988). Amphetamine injection into the ventral mesencephalon sensitizes rats to peripheral amphetamine and cocaine. J Pharmacol Exp Ther 245: 1095-1102.

Kauer JA, Malenka RC (2007). Synaptic plasticity and addiction. Nat Rev Neurosci 8: 844-858.

Kelly RS, Wightman RM (1987). Detection of dopamine overflow and diffusion with voltammetry in slices of rat brain. Brain Res 423: 79-87.

Knackstedt LA, Moussawi K, Lalumiere R, Schwendt M, Klugmann M, Kalivas PW (2010). Extinction training after cocaine selfadministration induces glutamatergic plasticity to inhibit cocaine seeking. J Neurosci 30: 7984-7992.

Knackstedt LA, Trantham-Davidson HL, Schwendt M (2014). The role of ventral and dorsal striatum mGluR5 in relapse to cocaineseeking and extinction learning. Addict Biol 19: 87-101.

Kombian SB, Malenka RC (1994). Simultaneous LTP of nonNMDA- and LTD of NMDA-receptor-mediated responses in the nucleus accumbens. Nature 368: 242-246.

Kourrich S, Klug JR, Mayford M, Thomas MJ (2012). AMPARindependent effect of striatal alphaCaMKII promotes the sensitization of cocaine reward. J Neurosci 32: 6578-6586.

Kourrich S, Rothwell PE, Klug JR, Thomas MJ (2007). Cocaine experience controls bidirectional synaptic plasticity in the nucleus accumbens. I Neurosci 27: 7921-7928.

Kourrich S, Thomas M (2009). Similar neurons, opposite adaptations: psychostimulant experience differentially alters firing properties in accumbens core versus shell. J Neurosci 29: $12275-12283$

Kumaresan V, Yuan M, Yee J, Famous KR, Anderson SM, Schmidt $\mathrm{HD}$ et al (2009). Metabotropic glutamate receptor 5 (mGluR5) antagonists attenuate cocaine priming- and cue-induced reinstatement of cocaine seeking. Behav Brain Res 202: 238-244.

Lee KW, Kim Y, Kim AM, Helmin K, Nairn AC, Greengard P (2006). Cocaine-induced dendritic spine formation in D1 and D2 dopamine receptor-containing medium spiny neurons in nucleus accumbens. Proc Natl Acad Sci USA 103: 3399-3404.

Liu Y, Morgan D, Roberts DC (2007). Cross-sensitization of the reinforcing effects of cocaine and amphetamine in rats. Psychopharmacology 195: 369-375.

Lobo MK, Covington HE 3rd, Chaudhury D, Friedman AK, Sun H, Damez-Werno D et al (2010). Cell type-specific loss of BDNF signaling mimics optogenetic control of cocaine reward. Science 330: 385-390.

Lujan R, Nusser Z, Roberts JD, Shigemoto R, Somogyi P (1996). Perisynaptic location of metabotropic glutamate receptors mGluR1 and mGluR5 on dendrites and dendritic spines in the rat hippocampus. Eur J Neurosci 8: 1488-1500.

Luscher C, Huber KM (2010). Group 1 mGluR-dependent synaptic long-term depression: mechanisms and implications for circuitry and disease. Neuron 65: 445-459.

Mangiavacchi S, Wolf ME (2004). Stimulation of N-methyl-Daspartate receptors, AMPA receptors or metabotropic glutamate receptors leads to rapid internalization of AMPA receptors in cultured nucleus accumbens neurons. Eur J Neurosci 20: 649-657.

McCutcheon JE, Loweth JA, Ford KA, Marinelli M, Wolf ME, Tseng KY (2011). Group I mGluR activation reverses cocaineinduced accumulation of calcium-permeable AMPA receptors in nucleus accumbens synapses via a protein kinase C-dependent mechanism. J Neurosci 31: 14536-14541.

McFarland K, Lapish CC, Kalivas PW (2003). Prefrontal glutamate release into the core of the nucleus accumbens mediates cocaineinduced reinstatement of drug-seeking behavior. J Neurosci 23: 3531-3537.

Moussawi K, Zhou W, Shen H, Reichel CM, See RE, Carr DB et al (2011). Reversing cocaine-induced synaptic potentiation provides enduring protection from relapse. Proc Natl Acad Sci USA 108: 385-390.

Naisbitt S, Kim E, Tu JC, Xiao B, Sala C, Valtschanoff J et al (1999). Shank, a novel family of postsynaptic density proteins that binds to the NMDA receptor/PSD-95/GKAP complex and cortactin. Neuron 23: 569-582.

Nelson CL, Milovanovic M, Wetter JB, Ford KA, Wolf ME (2009). Behavioral sensitization to amphetamine is not accompanied by changes in glutamate receptor surface expression in the rat nucleus accumbens. J Neurochem 109: 35-51.

Ortinski P, Vassoler F, Carlson G, Pierce R (2012). Temporally dependent changes in cocaine-induced synaptic plasticity in the nucleus accumbens shell are reversed by D1-like dopamine receptor stimulation. Neuropsychopharmacology 37: $1671-1682$

Park S, Park JM, Kim S, Kim JA, Shepherd JD, Smith-Hicks CL et al (2008). Elongation factor 2 and fragile $\mathrm{X}$ mental retardation protein control the dynamic translation of Arc/Arg3.1 essential for mGluR-LTD. Neuron 59: 70-83.

Park WK, Bari AA, Jey AR, Anderson SM, Spealman RD, Rowlett JK et al (2002). Cocaine administered into the medial prefrontal cortex reinstates cocaine-seeking behavior by increasing AMPA receptor-mediated glutamate transmission in the nucleus accumbens. J Neurosci 22: 2916-2925.

Pascoli V, Turiault M, Luscher C (2012). Reversal of cocaine-evoked synaptic potentiation resets drug-induced adaptive behaviour. Nature 481: 71-75.

Pennartz CM, Ameerun RF, Groenewegen HJ, Lopes da Silva FH (1993). Synaptic plasticity in an in vitro slice preparation of the rat nucleus accumbens. Eur J Neurosci 5: 107-117.

Pennartz CM, Boeijinga PH, Lopes da Silva FH (1990). Locally evoked potentials in slices of the rat nucleus accumbens: 
NMDA and non-NMDA receptor mediated components and modulation by GABA. Brain Res 529: 30-41.

Pierce R, Wolf M (2013). Psychostimulant-induced neuroadaptations in nucleus accumbens AMPA receptor transmission. Cold Spring Harb Perspect Med 3: a012021.

Pierce RC, Bell K, Duffy P, Kalivas PW (1996). Repeated cocaine augments excitatory amino acid transmission in the nucleus accumbens only in rats having developed behavioral sensitization. J Neurosci 16: 1550-1560.

Pierce RC, Kalivas PW (1995). Amphetamine produces sensitized increases in locomotion and extracellular dopamine preferentially in the nucleus accumbens shell of rats administered repeated cocaine. J Pharmacol Exp Ther 275: 1019-1029.

Pontieri F, Tanda G, Di Chiara G (1995). Intravenous cocaine, morphine, and amphetamine preferentially increase extracellular dopamine in the 'shell' as compared with the 'core' of the rat nucleus accumbens. Proc Natl Acad Sci USA 92: 12304-12308.

Reid M, Hsu K, Berger S (1997). Cocaine and amphetamine preferentially stimulate glutamate release in the limbic system: studies on the involvement of dopamine. Synapse (New York, NY) 27: 95-105.

Robbe D, Alonso G, Chaumont S, Bockaert J, Manzoni O (2002). Role of $\mathrm{p} / \mathrm{q}-\mathrm{Ca} 2+$ channels in metabotropic glutamate receptor 2/3-dependent presynaptic long-term depression at nucleus accumbens synapses. J Neurosci 22: 4346-4356.

Rothwell PE, Kourrich S, Thomas MJ (2011). Synaptic adaptations in the nucleus accumbens caused by experiences linked to relapse. Biol Psychiatry 69: 1124-1126.

Schilstrom B, Yaka R, Argilli E, Suvarna N, Schumann J, Chen BT et al (2006). Cocaine enhances NMDA receptor-mediated currents in ventral tegmental area cells via dopamine D5 receptor-dependent redistribution of NMDA receptors. J Neurosci 26: $8549-8558$.

Siciliano CA, Calipari ES, Jones SR (2014). Amphetamine potency varies with dopamine uptake rate across striatal subregions. $J$ Neurochem 131: 348-355.

Sun WL, Zhou L, Hazim R, Quinones-Jenab V, Jenab S (2007). Effects of acute cocaine on ERK and DARPP-32 phosphorylation pathways in the caudate-putamen of Fischer rats. Brain Res 1178: $12-19$.

Sun X, Milovanovic M, Zhao Y, Wolf ME (2008). Acute and chronic dopamine receptor stimulation modulates AMPA receptor trafficking in nucleus accumbens neurons cocultured with prefrontal cortex neurons. J Neurosci 28: 4216-4230.

Swanson CJ, Baker DA, Carson D, Worley PF, Kalivas PW (2001). Repeated cocaine administration attenuates group I metabotropic glutamate receptor-mediated glutamate release and behavioral activation: a potential role for Homer. J Neurosci 21: 9043-9052.

Tashev R, Moura PJ, Venkitaramani DV, Prosperetti C, Centonze D, Paul S et al (2009). A substrate trapping mutant form of striatal- enriched protein tyrosine phosphatase prevents amphetamineinduced stereotypies and long-term potentiation in the striatum. Biol Psychiatry 65: 637-645.

Thomas MJ, Beurrier C, Bonci A, Malenka RC (2001). Long-term depression in the nucleus accumbens: a neural correlate of behavioral sensitization to cocaine. Nat Neurosci 4: 1217-1223.

Tu JC, Xiao B, Naisbitt S, Yuan JP, Petralia RS, Brakeman P et al (1999). Coupling of mGluR/Homer and PSD-95 complexes by the Shank family of postsynaptic density proteins. Neuron 23: 583-592.

Uchimura N, Higashi H, Nishi S (1989). Membrane properties and synaptic responses of the guinea pig nucleus accumbens neurons in vitro. J Neurophysiol 61: 769-779.

Valjent E, Pascoli V, Svenningsson P, Paul S, Enslen H, Corvol JC et al (2005). Regulation of a protein phosphatase cascade allows convergent dopamine and glutamate signals to activate ERK in the striatum. Proc Natl Acad Sci USA 102: 491-496.

Vanderschuren LJ, Schmidt ED, De Vries TJ, Van Moorsel CA, Tilders FJ, Schoffelmeer AN (1999). A single exposure to amphetamine is sufficient to induce long-term behavioral, neuroendocrine, and neurochemical sensitization in rats. J Neurosci 19: 9579-9586.

Vezina P (2004). Sensitization of midbrain dopamine neuron reactivity and the self-administration of psychomotor stimulant drugs. Neurosci Biobehav Rev 27: 827-839.

Wang JQ, Tang Q, Parelkar NK, Liu Z, Samdani S, Choe ES et al (2004). Glutamate signaling to Ras-MAPK in striatal neurons: mechanisms for inducible gene expression and plasticity. Mol Neurobiol 29: 1-14.

Waung MW, Pfeiffer BE, Nosyreva ED, Ronesi JA, Huber KM (2008). Rapid translation of Arc/Arg3.1 selectively mediates mGluR-dependent LTD through persistent increases in AMPAR endocytosis rate. Neuron 59: 84-97.

Xue CJ, Ng JP, Li Y, Wolf ME (1996). Acute and repeated systemic amphetamine administration: effects on extracellular glutamate, aspartate, and serine levels in rat ventral tegmental area and nucleus accumbens. J Neurochem 67: 352-363.

Yasuda RP, Zahniser NR, Dunwiddie TV (1984). Electrophysiological effects of cocaine in the rat hippocampus in vitro. Neurosci Lett 45: 199-204.

Yin HH, Davis MI, Ronesi JA, Lovinger DM (2006). The role of protein synthesis in striatal long-term depression. J Neurosci 26: 11811-11820.

Zahm D, Brog J (1992). On the significance of subterritories in the 'accumbens' part of the rat ventral striatum. Neuroscience 50: 751-767.

Zhang Y, Venkitaramani DV, Gladding CM, Zhang Y, Kurup P, Molnar E et al (2008). The tyrosine phosphatase STEP mediates AMPA receptor endocytosis after metabotropic glutamate receptor stimulation. J Neurosci 28: 10561-10566. 